\title{
Developing a model for supervising social work students in groups
}

\section{Paul McCafferty ${ }^{1}$}

Summary: Much is written about group supervision in other health care fields; however less attention is paid to this topic in social work. This lack of scholarly attention became obvious to the author when he attempted to begin supervising students in groups and was unable to reference a suitable model or template of group supervision from which to gain ideas or direction. The author therefore decided to develop his own model of group supervision. The following article gives an account of how the author developed this model by critically appraising the relevant policy and theory from a local and national perspective to inform his practice.

Key Words: group supervision, critical appraisal

1. Manager, Practice Learning Centre, Partnership Care West, Derry, N Ireland

Address for Correspondence: Partnership Care West, 92 Spencer Road, Derry, BT47 6AG. Pmccafferty67@hotmail.com 


\section{Background}

When considering supervising students in groups, the author had been managing a practice learning centre in the voluntary sector in Northern Ireland. The centre was contracted to the Northern Ireland Social Care Council (NISCC) to provide placements in the voluntary sector for social work students undertaking professional training. These students were supervised individually by a practice teacher who was off site.

When reflecting on the quality and efficacy of this individual approach, several main themes emerged that were particularly relevant to the author in this practice situation.

Firstly, it was difficult to equalise the power imbalance that existed between the student and the individual practice teacher. This power imbalance existed on several levels, namely,

- Teacher/student,

- Perceived expert/non expert,

- Male/female, and

- Assessor/assessed.

Other power imbalances can exist in the supervisory relationship, including issues of race, age, disability, class, social status, culture and religious affiliation. These factors of power need to be recognised at the very beginning of the supervision process so that both supervisor and supervisee can relate to one another on a more equal footing and avoid the abuse of power that can easily influence the working relationships of both parties.

Secondly, the students learning experience was restricted by the one to one approach. Students felt isolated and unsupported without peer contact. This also led to a block in learning and a feeling of being alone.

Based on these thoughts, it was decided that one possible way to overcome these difficulties was to supervise the students in a group. In group supervision the facilitator/s meet with two or more students to provide educational, administrative and supportive supervision. It is seen as supervision only within a group setting. Its membership is clearly defined with identifiable aims and objectives and the process has a designated place in the formal structure of the agency. Group supervision would hopefully lead to a more equal relationship, enhance the learning

25 Journal of Practice Teaching 6(2) 2005, pp.24-42 $\quad$ (c) 2005 Whiting and Birch 
of the students and decrease the feelings of going it alone.

It was automatically assumed that the supervision of social work students in groups would be a popular and well researched subject, and that a template for a model would be available from which to gain directional ideas. However, an initial literature review demonstrated that although there is much material about group supervision and learning in the fields of counselling, psychotherapy, nursing, and occupational therapy, less has been written from a student social work perspective, the work of Sales and Navarre (1970), Shulman (1982), Hose (1987), Kruger et al (1987), Ford and Jones (1987), Brown (1994), Wilkins (1995), Shardlow and Doel (1996), Tebb et al (1996), Brown and Bourne (1996), Preston Shoot (1998), Walter and Young (1999), Arkin (1999), Kadushin and Harkness (2004), and Lindsay (2005) being exceptions.

The author therefore decided to develop his own model for group supervision, informed by critically appraising relevant theories and policies from a local and national perspective. In this article, the author outlines that process beginning with a definition of what critical appraisal is, discussing its importance in social work and continues by critically appraising the policies and theory that are relevant to group supervision. The article outlines the model of group supervision that was developed as a result of this process, discussing the advantages and disadvantages of the model and then offers some practice guidance to practitioners who may wish to offer group supervision to their students.

\section{Introduction}

What actually constitutes critical appraisal, and what relevance does critical appraisal have to social work? Gambrill (2000, p.43), states that critical appraisal is the

careful appraisal of beliefs and actions to arrive at well reasoned ones that maximise the likelihood of helping. It involves reasonable and reflective thinking focused on deciding what to do or believe.

Brechin (2000, p.26) expands this definition stating that critical appraisal is 'open minded reflective appraisal that takes account of

26 Journal of Practice Teaching 6(2) 2005, pp.24-42 $\quad$ (C) 2005 Whiting and Birch 
different perspectives, experiences and assumptions.' Critical appraisal gives us a way of organising our thinking and doing to respond to uncertainty and risk (Adams et al., 2002).

The relevance of critical thinking to social work is outlined by the National Association of Social Workers (NASW, 1996), which advises social workers to 'critically examine and keep current with emerging knowledge relevant to social work' and 'fully use evaluation and research evidence in their professional practice' (standard 5.02). Critical appraisal is also relevant to Value 6 of the NASW code of ethics, which calls on social workers to 'practice within their areas of competence and to develop and enhance their professional expertise' (NASW, 1996, p. 6).

Moreover, only if social workers are aware of common biases and develop skills to counter them, can such biases be minimised. Critical appraisal, knowledge, skills and values can help social workers to critically appraise claims and arguments, use language effectively, recognise affective influences on decisions, avoid cognitive biases that interfere with sound decision making, and spot pseudoscience and so help avoid their influence (Grambrill, 2000). By adopting the principles inherent in the concept of critical appraisal, the author was able to examine the policies and theories relevant to group supervision and thereby develop his own model as a result.

The first issue of relevance relates to the policies and legislation in this area. To begin with, when the new Diploma in Social Work (DipSW) was introduced nationally in 1989, it was CCETSW who, having derived its overall powers from The Health and Social Services and Social Security Adjudication Act 1983 and a direction under Section 10(11)(A) of the Act, decreed that practice placements were essential to social work training. Practice placements provided the opportunity for assessing students' competence to practice and, therefore, to be awarded the DipSW. CCETSW also recognised that practice placements allowed students to apply the theory of their training in a supervised setting and to develop and practice the range of social work skills in a work environment (CCETSW, 1998).

CCETSW argued that the assessment of students should be completed mainly through supervision and that this supervision should be carried out by a qualified practice teacher. This aspiration is reflected locally in Northern Ireland in the Training Organisation for the Personal Social Services, (TOPPS). In A First Class Service, Training Strategy 2000-2003 
(TOPPS, 2000) TOPPS aspired to have eighty per-cent of all DipSW practice placements supervised by award holding practice teachers.

To qualify as a practice teacher one had to complete the practice teachers award. This award is regulated nationally by CCETSW, with statutory authority under Section 4 iii c of the Health and Social Services and Social Security Adjudication Act 1983, which allows CCETSW to regulate the various local practice teacher award programmes. CCETSW outlined 14 requirements for the Practice Teaching Award in Paper 26.3 (CCETSW, 1991). These could be interpreted locally, provided that national standards were reflected. With regards to supervision, it was expected that students would be given a minimum of one and a half hours per week.

The functions of CCETSW were subsumed by the Northern Ireland Social Care Council (NISCC) and TOPPS in Northern Ireland. NISCC is a statutory body established by the Health and Personal Social Services Act (Northern Ireland) 2001. The main purpose of NISCC is to regulate the social care workforce and its education and training (NISCC, 2003). The DiPSW is being replaced by the new three-year Bachelor of Social Work degree and students will undergo supervised practice in year two and three.

An indication of the new arrangements for supervision and its importance can be derived from the Codes of Practice for Social Care Workers and Employers of Social Care Workers NISCC (2003). Code 6 for employees states

as a social care worker, you must be accountable for the quality of your work and take responsibility for maintaining and improving your knowledge and skills

and code two for employers states

as a social care employer, you must have written policies and procedures in place to enable social care workers to meet the NISCC's Code of Practice for Social Care Workers.

This includes under code 2.2 'effectively managing and supervising staff', NISCC (2003). Supervising students to achieve competence is therefore seen as essential to their professional development and this idea is enshrined in the current policies of NISCC. Less is said 
about the form that supervision is to take and no guidelines for the format of supervision exist. It appears that practice teachers are able to exercise their professional judgement when deciding on the format for supervising students so long as that format achieves the agreed aims and objectives of professional supervision as set out in the policies described above.

A critical appraisal of the theory related to group supervision also helped the author develop his model for group supervision. To begin with however, it is important to briefly define what theory is and discuss why it is important for social workers to have an understanding of theory.

Compton and Galaway (1979, p.41, quoted in Thompson, 2000, p.24) define theory as

a coherent group of general propositions or concepts used as principles of explanation for a class of phenomenon - a more or less verified or established explanation accounting for known facts or phenomena and their interrelationship

According to Howe (1997) if social workers are to act competently in situations of continuous flux, then they must have a theory or theories to make sense of that which is complex and disordered. There must be a conscious attempt to theorise and thereby gain insight and understanding. If social workers did not theorise then their world would remain a cauldron of unorganised experience and practical action would remain impossible. There were four main theories that were influential in helping the author organise his thinking regarding the organisation, content, format, style and approach when developing his model for group supervision. These theories are supervision theory, adult learning theory, group work theory and anti oppressive practice theory.

With regards to supervision theory, it is clear to see from examining the literature that traditionally, supervision has tended to be a one to one activity between practice teacher and student. This type of supervision has been described as a "process by which one social work practitioner enables another social work practitioner who is accountable to him to practice to the best of his ability' (Pettes, 1967, p.3). Group supervision takes this process a step further and has been described as 'a regular pattern of focused discussion between' practice 'teacher and two or more supervisees', where the emphasis is on 'group problem solving' (Challis

29 Journal of Practice Teaching 6(2) 2005, pp.24-42 @ 2005 Whiting and Birch 
$\&$ Davis, 1986), or as the use of the group setting to implement the responsibilities of supervision (Kadushin \& Harkness, 2002).

It is evident however that supervision is both central and marginal to social work. It is central because the most vital social work resources are the personal resources of the workers (Payne $\&$ Scott, 1982). It is marginal because in practice its efficacy is undermined by lack of commitment. A result of this is that supervision in terms of regularity, content and outcome is patchy and variable in quality (Pritchard, 1995). This ambivalence is reinforced by the current political context. Critical enquires into child abuse at local and national level, legislative changes, and the emphasis on delivering value for money has rendered supervision synonymous with bureaucratic control. As a consequence, one purpose of supervision has been described as establishing 'accountability of the worker to the organisation' (Parsole and Hill, 1978). Unfortunately, emphasis on one purpose risks disturbing the balance with the other, 'to promote the worker's development as a professional' (Parsole and Hill, 1978). As the two purposes are seen as practically and conceptually interwoven, disruption in practical application leads to confusion and ultimately resistance (Pritchard, 1995).

The challenge for the author when developing his model was to manage these tensions, while at the same time, carrying out what is more recently agreed as the five main functions of supervision. These functions are administration, teaching, helping (Pettes, 1967), mediation (Richards et al., 1991; Morrison, 1990), and assessment (Evans, 1990; Sawdon \& Sawdon, 1995). It was therefore important to have an overarching theoretical construct to give the author an overall philosophy of purpose to manage these tensions and at the same time carry out those functions. The theory of adult learning - the second theory used in developing the model for group supervision - was critical. Understanding how people learn is essential if any supervision process is to be effective. Knowles (1978) invites us to challenge objective pedagogic approaches to teaching and to consider androgogy, which is seen as the art of enabling adults to learn. Knowles' concept of androgogy is based on four assumptions of the adult learner. These are:

- As a person matures, their self-concept moves from a dependant personality towards self-direction.

- They accumulate a growing reservoir of experience that becomes an increasing resource for learning.

30 Journal of Practice Teaching 6(2) 2005, pp.24-42 @ 2005 Whiting and Birch 
- Their readiness to learn becomes oriented to the developmental tasks of their social roles.

- Their time perspective changes from one of postponed application of knowledge to immediacy of application, and accordingly her/his orientation towards learning shifts from one of subject centeredness to one of problem centeredness.

In this light, it was important for the author to be seen as a facilitator, joining with the students/supervisees in a process of enquiry rather than as an expert imparting knowledge (Pritchard, 1995). This set the tone for the group and was helpful in deciding on issues such as content, teaching style, approach, structure, methods of delivery and assessment methods.

The third helpful theory was that of groupwork. The areas where this theory was most helpful included: considering the advantages of group work as a method; planning and contracting; and co-working.

The work of Alan Brown (1994) was useful in this regard. Brown states that the advantages of group work include,

Much social living is experienced in groups. A natural group is real life and a created group provides a setting where problems of interpersonal relationships and skills can be worked on first hand. This view is also shared by Adams (2002) who suggests that working with students in groups, can effectively enhance their understanding of the real life interpersonal problems that affect service users:

- Groups of people with similar needs can be a source of mutual support and problem solving.

- Attitudes, feelings and behaviour may be changed in groups.

- In a group, every member is a potential helper.

- A group can be democratic and self determining, giving more power to the participant.

Brown also points out however that there could be several disadvantages to the group work approach, which include:

- Confidentiality is much more difficult to maintain.

- Groups can be difficult to organise, plan and implement.

- Individuals get less attention.

- Groups can be limiting to a small majority.

31 Journal of Practice Teaching 6(2) 2005, pp.24-42 @ 2005 Whiting and Birch 
On balance however, Rogers (1994) argues that group work in adult education can be an excellent forum in which the educational lives of adults can be enriched extensively by the group process.

Brown (1994) was also helpful when it came to contemplating the planning and contracting stage of the group. Brown argues that this is a critical stage in the life of a group and that the success of this stage will determine the tone and outcome of the rest of the group. Brown suggests that there are three stages to consider at this time. Firstly, there must be a need for the group to exist, which was established when it was recognised that the individual approach had its limitations. Secondly, there must be organisational support, which was firmly in place before the group began. Thirdly, the practicalities of the group must be organised, which meant booking the room, having the resources allocated, ensuring the times were worked out and ensuring that adequate materials were at hand.

Brown (1994) and Benson (1987) were also useful when considering the notion of the contract. This is drawn up with the students at the initial tripartite meeting between the student, the tutor and the practice teacher. At the tripartite a detailed discussion takes place in relation to the student's learning needs, the learning style of the student, and the role and function of supervision, and how to match the needs of the student to the type of supervision that they will receive. It is also important to discuss any additional requirements of the student that will influence the type of supervision that they will receive. A discussion then takes place about group supervision and if all parties feel that group supervision will meet the needs of the student, a three way decision is taken to offer group supervision during the placement. Additionally, it is pointed out to the student that the second practice teacher who usually co-facilitates the group will also contribute to the overall assessment. This is important because the student must give clear approval for this before group supervision begins.

At this stage the author has recognised that a disparity of access exists between students. Group supervision is only offered to students with whom the author works; even if it is recognised that a student in an other instance would benefit from group supervision, it is not offered because few practice teachers have the experience or skills to work in this way. The student then misses a potentially enriching experience that would aid them in their professional development. In an effort to 
bridge this gap in the skills and knowledge of local practice teachers the author now provides training to the local practice teaching award programme. This will hopefully ensure that more and more practice teachers have the ability to offer this type of supervision and therefore widen the accessibility of group supervision to those students that would benefit from this approach.

Once the process of group supervision starts an additional contract is drawn up with the students in the first session. This contract specifically relates to the actual workings of the group and the group agree a set of ground rules that will enable the group to run effectively. Brown argues that contracting has two main advantages. One is the acknowledgement that users of the service have the right to participate in decisions about the form of service they are to receive. The other is a technique that attempts to be more explicit about the methods to be used and the mutual obligations of everyone concerned. It was important to take time over this stage and ensure that all members felt comfortable with the finished contract. Each point needs careful exploration as students sometimes raise points that are unrealistic and which cannot be accommodated within the group; for example the request for total confidentiality cannot be assured. These type of issues must be discussed carefully with skill and understanding, and at the same time the facilitator must adhere to the social work values of partnership, inclusion, citizenship, rights and responsibilities.

Drawing up the contract was empowering for the students and avoided oppression in a relationship that was potentially oppressive. It was important therefore to appraise the theory of anti-oppressive practice to ensure the model was developed in line with the anti-oppressive ethos. This was essential because if we believe Brown (1994) that all groups are a microcosm of society, then the same issues of oppression in the wider society will be reflected in the group. For the author personally, one of the most striking issues of relevance in this regard was the fact that most of the members were female. In situations such as this, there is a danger of the male worker displaying sexist attitudes. Sexism has been defined as

a deep routed, often unconscious system of beliefs, attitudes and institutions in which distinctions about peoples worth are made on the grounds of their sex. (Bullock and Stallybrass, 1977, p.571, in Thompson 2001) 
This issue is encapsulated well by Thompson (2001) who states that oppression can be seen on three levels. These levels are structural, cultural and personal. Structural denotes the socio/political dimension of interlocking patterns of power and influence. Cultural denotes the commonalities of patterns of thought and behaviour. Personal denotes individual levels of thought, feelings, attitudes and actions. Thompson states that sexism is so powerful in society that it operates on all three levels. Of crucial importance in combating sexist behaviour and attitudes and incorporating the value of respect within the model, was the effectiveness of the co-working relationship between the facilitators. Hodge (1985) argues that a benefit of co-working is that the leaders can model specific social and interactional skills. This is especially true when a male /female relationship can exemplify mutual respect. It was therefore important to share tasks, give verbal support, give feedback, checkout issues relating to behaviour, and challenge any negative attitudes. This involved thorough preparation and open and honest debriefing.

\section{The model}

The model that the author devised consisted of seven group sessions and seven individual sessions. These sessions alternated each week, so one week the students came together in a group and the next week the students were seen individually. Before the group started, the facilitators met to prepare for the forthcoming session, feeling that this stage was crucial to the success of the group (Douglas, 1970). The facilitators checked in with one another on a cognitive and emotional level, ensuring they were fully prepared for the forthcoming session. They also ensured that they had divided the tasks equally between themselves, thus ensuring they were modelling good partnership relationships for the students.

The group sessions themselves had a set agenda for each week and examine particular social work topics. These could include: contracting, assessment, care planning reviewing, evaluating process records, the theory and practice of social work, values in social work, self assessment and evaluation of skills, the importance of reflection in social work, the application of anti oppressive practice, and portfolio construction.

34 Journal of Practice Teaching 6(2) 2005, pp.24-42 $\quad$ (C) 2005 Whiting and Birch 
The content of each session was purposely generic, as each of the students was placed in different placement sites, with a different serviceuser group. The content of the sessions did not have to stay the same and could be changed with the mutual consent of the facilitators and students. The point is however, that there was a main theme each week. The group sessions all worked to a set format which meant that each week the group began with an ice-breaker, which the students choose. This worked to get the members loosened up and created a relaxed and supportive environment. The facilitators then had a check-in, during which time individuals were given the space to discuss with the group, the interventions that they experienced with service users that week. Hillerbrand (1989) found that intervention skills are enhanced in this way as a result of the verbalisation of the cognitive processes of students in peer groups, and that conceptualisation is more effective within peer groups than under the guidance of an instructor (Arkin, 1999).

After this section the group takes a break and the facilitators leave the students by themselves. This was important as it gave the students a period of time together and resulted in the students feeling a greater sense of solidarity and cohesion. (When the group finished at the end of placement, the students themselves commented that this was one of the most valuable aspects of being in a group.) Time was then spent on the main topic for that week which was explored in depth. This process of exploration was completed by using role plays, presentations, group exercises, vignettes, group discussions, and homework exercises. Inspiration for some of the exercises came from two useful practice teaching tool kits, one by Traynor et al., Branching Out, and one by the Voluntary Organisations Forum (VOF) in partnership with The Eastern Health and Social Services Board, A Practice Teaching Tool-kit. All sessions lasted three hours, and at the end of each session, the students were given some work to do for the next session. When the group sessions finished, the facilitators met to debrief. A simple format was used to give some structure to this process and each week, as a means of evaluation, the facilitators looked at their thoughts regarding how well the session had gone, the actual facts of what took place and what the facilitators were experiencing on an emotional level.

At the contracting stage, students were made aware that the entire process of group supervision was assessed, and this was agreed with the tutor at the initial tripartite. Each facilitator retains the overall summative assessment responsibility for a designated student and at the very 
end of the placement the practice teacher writes an assessment report which relates directly to the requirements of the university and which is included in their portfolios. This assessment is also triangulated with the formative assessment of the co-facilitator, live observations, individual supervision and feedback from on-site supervisors and service users and work that was required from the individual courses.

When making assessments the facilitators examined the standard of some of the student's written work such as process records and reports required for the respective agencies, such as assessments and care plans. For example, if a student was required to make an assessment on a service user, the standard of that assessment would be analysed to ensure the student understood the theory that guided assessment work and that the student understood the practical approach to making accurate assessments in partnership with service users. This service user assessment could then be transferred into the student's portfolio as evidence of their ability to meet the course requirements, and to provide evidence of their competency to practice. Assessments were also based on the ability of the students to discuss theory and make connections to practice, their ability to engage with other students and the facilitators, their ability to engage in exercises that looked at issues such as personal values and how these influence our practice and their ability to reflect on case material and outline the skills required to practice competently. Exercises that were used to generate discussion could also be used by the students as evidence in their portfolios. For example, if a student completed an exercise on the examination of their values, the exercise sheets could be put into their portfolios as evidence of their development as practitioners who work under strict ethical guidelines or as practitioners who can navigate a complex ethical dilemma. Therefore, the evidence that the students produced (on the practical tasks for social work such as assessments, care planning and reviewing, and on more theoretical issues such as the examination of their values, the application of anti oppressive practice and the theoretical discussions that took place in the group) could all be used to demonstrate their competency and could therefore be transferred into their portfolios.

This process however brings challenges for the practice teacher in relation to the assessment. As the co-facilitator adds to the assessment the practice teacher needs to ensure equity with students who are only being assessed by one practice teacher. It is important that the student is treated fairly and not overly assessed. This is why it is critical at the beginning of the placement to discuss this issue with the student and 
the tutor. A clear contract outlining the roles and responsibilities of the practice teacher's co-facilitator is critical to ensure the student agrees to this form of assessment and that they know explicitly that another practice teacher will be adding to their assessment.

\section{Advantages and disadvantages}

Using this simple format, the facilitators were able to discern that the group process proved to be supportive (Winnicott, 1989) and provided an opportunity for students to meet who would otherwise be isolated. It also provided an opportunity for students to share different experiences. Group supervision can be less threatening and more likely to provide an environment in which it is safe to get it wrong. This appeared to come about as a result of individuals feeling more confident to express their views and less afraid to make mistakes because they had the support of their peers. Members felt affirmed by one another and those who appeared to struggle with the application and analysis of theory on an individual basis faired better in the group.

Group supervision also provided a containing experience (Bion, 1962) for the students and helped normalise anxieties. The students became more engaged in the process of learning, using the group as a forum for discussion and debate. This enabled the group to attain a deeper understanding of the skills and values necessary for professional practice. As a result, there was a greater sense of group and professional identity (Ford \& Jones, 1987; Wilkins, 1995). This sense of a learner identity, helped weaker members too, who were able to compare standards, get ideas to develop their own work, and provided a much needed sense of belonging (Kadushin, 1985). The group process also led to a decrease in the sense of expert/non-expert which also permitted the group to explore issues together as adults, rather than in the teacher/student relationship, which can be inhibiting. Additionally, students appeared to take constructive criticism more easily from their peers than from the facilitators.

On a less positive note however, the facilitators discovered that it was difficult to keep a rhythm of work going - for example to set work this week, read it, and provide feedback next week. A topic based agenda can be inflexible and therefore fail to meet individual learning needs on an ongoing basis. Students can feel embarrassed if feedback is negative

37 Journal of Practice Teaching 6(2) 2005, pp.24-42 $\quad$ (c) 2005 Whiting and Birch 
and they can feel inadequate if unable to answer questions. Additionally, some students can fail to see the relevance of others' input if they are not in the same placement site.

\section{Practice guidance}

Based on these findings, the author has developed some practice guidelines that can be used for practitioners who wish to undertake this type of supervision.

Principles of good group work practice apply equally to group learning on placement, especially in relation to planning, preparation, facilitation and co-facilitation. It is therefore vital that facilitators spend a considerable amount of time at the preparation stage. The facilitators must begin to discuss issues such as theoretical inclinations, personal issues that may impact on the running of the group, power issues regarding gender, structural position in the organisation, and the practicalities of running a group. Other issues to consider include deciding on the size of the group, the number of sessions to be conducted, the supervision arrangements for facilitators, the outline and content of the programme, and the roles that each facilitator will have and the tasks they complete. Finally, the facilitators must decide on how the group will end and what method of recording will be used.

Students find group supervision most useful when it fully exploits the learning opportunities that can take place in groups. Learning is enhanced by the opportunity for them to compare learning and progress with peers. Student learning is enriched by opportunities to give and receive support from peers. It is therefore vital that students be given time to discuss these issues in the presence of the other members in a supportive and enabling environment. This requires the facilitators to establish effective communication skills with each individual in the group, the group as a whole, between members, with any external persons relevant to the group and with the co-facilitator (Brown, 1992).

Students learn best in situations that are supportive and unthreatening. Student learning is adversely affected when, in the presence of peers, they are given negative feedback, compared unfavourably, or put on the spot in terms of knowledge. It is therefore important that any such feedback is given on an individual basis. This is why the model of 
alternating group sessions with individual sessions works well.

Students gain most from being in groups constructed of students who are in the same year as themselves. Students feel intimidated by the presence of other students who are at a more advanced stage. It is important therefore to have students in the same year as each other.

Students learn best when the content of sessions has a bearing on their practice experience. It is therefore important to keep sessions grounded in practice. Use of real life situations and case studies that represent the issues faced by workers in the actual placement themselves work well. It is important therefore to keep up to date with practice developments in any given agency.

A system of alternate sessions of individual and group supervision is emerging as the best model as this helps support students who may have a different learning style or who are struggling with the content of the group sessions.

This model for supervision is now embedded in the work of the practice learning centre and is no longer seen as an optional extra that may or may not be used. The model is now seen as integral to the way in which students at the practice learning centre are supervised. Naturally, not all practice teachers are in a position to work with the numbers that would make a group viable. However where the numbers do permit, this model could be tried. Finally, initial feedback from the students suggests that they gained a lot from this approach which should be encouraging to other practice teachers thinking about trying out this approach and is an area that the author hopes to explore further.

\section{Conclusion}

Critical appraisal, as an approach in social work, is essential if the profession is to remain dynamic and organic and if practice is to keep pace with the many challenges that social workers face. Thinking critically is one way to advance practice and adapt to change and it also enables us to question taken for granted assumptions and respond imaginatively. Critical appraisal informs and transforms practice in a rigorous manner and offers an alternative way of seeing reality. In this article, the author has outlined how he has informed and transformed his practice by critically appraising the theories and policies in relation to supervision in an attempt to respond

39 Journal of Practice Teaching 6(2) 2005, pp.24-42 $\quad$ (c) 2005 Whiting and Birch 
imaginatively to the identified limitations of one to one supervision. The article outlines the model of group supervision that was developed as a result of the critical appraisal and discusses the advantages and disadvantages of the model. The article then offers some practice guidelines for others who may wish to use group supervision as an alternative to the traditional one to one approach.

\section{References}

Adams, R., Dominelli, L., and Payne, M. (2002) Critical Practice in Social Work. Basingstoke: Palgrave

Arkin, N., Freund. A., and Saltman, I. (1999) A group supervision model for broadening multiple-method skills of social work students. Social Work Education, 18, 1, 49-58

Benson, J. (1987) Working more Creatively with Groups. London: Tavistock Publications

Bion, W.R. (1962) Learning from Experience. London: Heinmann

Brechin, A. (2000) Introducing critical practice. in A. Brechin, H. Brown, and. M. Eby, Critical Practice in Health and Social Care. London: Open University/Sage

Brown, A. (1994) Group Work. (3rd ed.) Aldershot: Ashgate

Brown, A. and Bourne (1996) The Social Work Supervisor. Buckingham: Open University Press.

CCETSW (1998) Review Stage Two, Northern Ireland Report. Belfast: DHSSPS

CCETSW (1991) Practice Teaching Award. Paper 26.3. London: CCETSW

Challis, D., and Davis, B. (1986) Case Management in Community Care. Aldershot: Gower

Compton, B.R., and Galaway, R.R. (1979) Social Work Process. Homewood IL: Dorsey Press in Thompson, N. (2000) Theory and Practice in Human Services, Open University Press, Maidenhead

Douglas, T. (1970) A Decade of Small Group Theory 1960/70. London: Bookstall Publications

Evans, D. (1990) Assessing Students' Competence to Practice. London: CCETSW

Ford, K., and Jones, A. (1987) Students Supervision. London, Macmillan

Gambrill, E. (2000) The role of critical thinking in evidence based social work. in P. Allen-Meares and C. Garvin (Eds.) The Handbook of Social Work Direct Practice. Thousand Oaks, CA: Sage

Health and Social Services and Social Security Adjudications Act (1983). Part 3,

40 Journal of Practice Teaching 6(2) 2005, pp.24-42 $\quad$ (C) 2005 Whiting and Birch 
Section 10

Hillerbrand, E. (1989) Cognitive differences between experts and novices: Implications for group supervision. Journal of counselling and development, 67, 5, 293-296

Hodge, J. (1985) Planning for Co-Leadership. A practice guide for practitioners. Newcastle: Groupvine

Hoese J. (1987) An exploratory investigation of group supervision. trainees, supervisors and structure. in A. Kadushin and D. Harkness Supervision in Social Work (4th ed ) New York: Columbia University Press

Howe, D. (1997) in The Blackwell Companion to Social Work. (2nd ed.) Oxford: Blackwell

Humphries, B. (1988) Adult learning in social work education: towards liberation or domestication? Critical Social Policy, 23, 4-21

Kadushin, A. (1985) Supervision in Social Work. (2nd ed.) New York: Columbia University Press

Kadushin, A., and Harkness, D. (2002) Supervision in Social Work. (4th ed.) New York: Columbia University Press

Knowles, M. (1978) The Adult Learner: A neglected species. Engelwood, N.J: Prentice Hall

Kruger L et al (1987) Group Supervision of Paraprofessional Counsellors. Professional Psychology. Research \& Practice 19 (6) 609-16 in Kadushin, A and Harkness, D (2002) Supervision in Social Work. (4th ed.) Columbia University Press New York.

Lindsay, T. (2005) Group learning on social work placements. Groupwork, 15, 1, 61-90

Morrison, T. (1990) The emotional effects on the worker, in the child protection system. Practice 4, 4, 253-271

National Association of Social Workers. (1996) Code of Ethics. Washington D C: NASW

NISCC, (2003) Codes of Practice for Social Care Workers and Employers of Social Care Workers. Belfast: DHSSPS

NISCC (2003) Northern Ireland Framework Specification for the New Degree in Social Work. Belfast: DHSSPS

Parsole, P., and Hill, M. (1978) Social Services Teams: A practitioner's view. London: DHSS/HMSO

Payne, C., and Scott, T. (1982) Developing Supervision in Field and Residential Settings. London: National institute for social work

Payne, M.E. (1967) Staff and Student Supervision: A Task centred approach.London George Allen and Unwin

41 Journal of Practice Teaching 6(2) 2005, pp.24-42 $\quad$ (c) 2005 Whiting and Birch 
Pettes, D. E. (1967) Staff and Student Supervision: A Task Centred Approach,.London: George Allen and Unwin

Preston-Shoot, M. (1995) Assessing anti-oppressive practice. Social Work Education, $14,2,11-27$

Pritchard, J. (1995) Good Practice in Supervision. London: Jessica Kingsley

Richards, M. et al. (1991) Staff Supervision in Child Protection Work. London: National Institute for Social Work

Rogers, A. (1994) Teaching Adults. Buckingham: Open university Press

Pritchard, J. (1995) Good Practice in Supervision. London: Jessica Kingsley

Sales, E., and Navarre, E. (1970) Individual and group supervision in field instruction. in C. Walter, and T. Young 1999) Combining Individual and Group Supervision in Educating for the Social Work Profession. Binghampton, NY: Haworth

Shulman, L. (1982) Skills of Supervision and Staff Management. Itasca, Il: Peacock.

Shardlow, S., and Doel, M. (1996) Practice Learning and Teaching. Basingstoke: Macmillan/BASW.

Sawdon, D.T., and Sawdon, C. (1995) Developing staff supervision and appraisal in the Probation Service. in J. Pritchard Good Practice in Supervision. London: Jessica Kingsley

Tebb, S., Manning, D., and Klaumann, T. (1996) A renaissance of group supervision in practicum. The Clinical Supervisor, 14, 39-51.

Thompson, N. (2000) Theory and Practice in Human Services. Maidenhead: Open University Press

Thompson, N. (2001) Anti Discriminatory Practice. (3rd ed.) Basingstoke: Palgrave

TOPPS (2000) A First Class Service, Training Strategy. Belfast: TOPPS Northern Ireland

Traynor, C. Et al (no date) Branching Out. Promoting Excellence in Practice Teaching. Belfast: Voluntary Organisations Forum

Voluntary Organisations Forum/Eastern Health and Social Services Board, (no date), A Practice Teaching Tool-kit. No publisher

Wilkins, D. (1995) A creative therapies model for the group supervision of counsellors, British Journal of guidance and counselling, 22, 1, 127-141

Walter, C.A., and Young, T.M. (1999) Combining individual and group supervision in educating for the social work profession, The Clinical Supervisor, 18, 2,

Winnicott, D.W. (1989) The Mother-infant experience of mutuality. (written in 1969). in C. Winnicott, R. Sheperd, M. Davis (Eds.) Psychoanalytic Explorations. Cambridge, MA: Harvard University Press

42 Journal of Practice Teaching 6(2) 2005, pp.24-42 $\quad$ (C) 2005 Whiting and Birch 